\title{
ANÁLISE COMPARATIVA ENTRE PROCESSOS DE FABRICAÇÃO ATRAVÉS DE SIMULAÇÕES DO SOFTWARE ARENA
}

\author{
Andressa Morais Aprigio (FIC/UNIS) - andressamorais2016@gmail.com \\ Gabriel Carrara Theodoro Garcia de Paula (FIC/UNIS) - carrara.gabriel@outlook.com \\ Lívia Iglésias Corrêa de Paiva (FIC/UNIS) - livia_icp@ hotmail.com \\ Marcos Felipe B. Saldanha (FIC/UNIS) - marfelipesaldanha8@ gmail.com \\ Tiago Bittencourt Nazaré (FIC/UNIS) - tiago@unis.edu.br
}

\begin{abstract}
RESUMO: O presente artigo trata-se de um estudo de caso em uma empresa do setor metalúrgico situada no município de Cataguases - MG. Tem como objetivo destacar melhorias nos processos através de comparações de dois modelos de simulações dos processos produtivos pelo software Arena 14, um referente ao modelo lógico adotado pela empresa em estudo e outro modelo proposto pelos autores, baseando-se nos valores da hora-máquina e da matéria-prima. A peça escolhida para o presente estudo é uma Porca Sextavada, confeccionada em aço SAE 1020, tendo um total de 40 itens produzidos. Sua fabricação foi dividida em 7 processos de usinagem e cada processo foi cronometrado. Para análise dos dados foi utilizado o software Minitab 18. Ao final da análise dos resultados, concluiu-se que os objetivos do trabalho foram alcançados, obtendo-se 40,04\% na redução do tempo de produção total de peças e um ganho econômico de $9,18 \%$, provando que a implementação do modelo proposto pelos autores seria benéfica para a empresa e a manteria competitiva no mercado de usinagem.
\end{abstract}

Palavras-chave: Usinagem. Modelo lógico. Arena. Simulações.

\section{INTRODUÇÃO}

Atualmente, a sobrevivência de uma empresa depende das capacidades de competir, de mudar e de desenvolver novas direções estratégicas. O pensar o novo, considerar ideias e soluções que ainda são desconhecidas, exibe uma função importante em adquirir uma vantagem competitiva. Portanto, percebe-se a urgência de buscar na literatura características ou aspectos essenciais para gerar a competitividade nas empresas.

As vantagens competitivas são um conjunto constante de características que a empresa possui, e esta contribui para um aumento da competitividade da organização. Entende-se como fator competitivo aquilo que representa uma real atenção e justificativa de cada atividade da empresa. Essas "justificativas" se compõem em particularidades que, ao serem identificadas, contribuem para o aprimoramento da organização, ou mais exclusivamente, para o aumento do desempenho.

A competitividade equivale aos fatores que a organização necessita para mostrar um bom desempenho, para sobreviver e se realçar em relação ao mercado. $\mathrm{O}$ estudo dos elementos que geram competitividade é necessário para que a empresa busque o desenvolvimento de produtos e 
processos corretamente, com a aplicação das melhores práticas em custos e em qualidade, registrando a necessidade do consumidor final. A análise dos fatores de competitividade é necessária para que a organização obtenha desempenhos melhores, atendendo desse modo, os requisitos de sua missão, de seus objetivos estratégicos e de sua visão de futuro.

O objetivo deste artigo, portanto, consiste em destacar as melhorias nos processos e detectar qual a melhor escolha para a empresa objeto de estudo através de simulações dos processos produtivos pelo software Arena 14, a fim de descrever os processos de usinagem, analisar os dados obtidos das peças estudadas, identificar onde existe menor tempo de usinagem e realizar um comparativo financeiro entre os cenários simulados tendo como base os valores da hora-máquina e da matéria-prima.

O tema justifica-se pela importância do setor de usinagem, com relação à produção de equipamentos para diversos segmentos da economia mundial, dos custos dos mesmos e a influência que a usinagem tem no Produto Interno Bruto (PIB) em 2019 que, conforme o site Usinagem Brasil (2019), o Instituto Brasileiro de Geografia e Estatística (IBGE) divulgou a redução em 1,7\%, comparado ao primeiro trimestre de 2018. Segundo o IBGE este resultado se deve à queda da fabricação de equipamentos de transportes, indústria farmacêutica, fabricação de máquinas e equipamentos e fabricação de produtos alimentícios.

No decorrer do artigo será mostrado como foi feita toda a análise dos dados coletados em uma empresa de usinagem de precisão na cidade de Cataguases no interior de Minas Gerais, onde é responsável em moldar materiais, tais como o aço carbono, inox, fundido, latão e bronze em peças industriais, entre outros, utilizando técnicas, ferramentas e máquinas de usinagem. No processo industrial, o material passa por uma série de etapas até chegar ao produto final.

\section{REFERENCIAL TEÓRICO}

\subsection{Usinagem}

O processo de usinagem trata-se de uma das atividades de destaque no que se refere ao crescimento econômico global. Pesquisas de desenvolvimento deste tipo de processo buscam melhorias do desempenho através de ferramentas mais avançadas, variedade de materiais, maior capacidade de produção e qualidade (PUSAVEC et al., 2014).

Vastas investigações são de extrema relevância no processo de usinagem, objetivando 
definir parâmetros eficientes do processo para que condições mais eficazes sejam alcançadas (SARIKAYA; GÜLLÜ, 2014).

Os principais aspectos da usinagem são interação entre a máquina e ferramentas utilizadas e a peça a ser usinada. Para que esses três aspectos estejam relacionados, é necessário conhecê-los profundamente, para que haja a otimização do tempo e recursos utilizados durante o processo de usinagem (MONTEMEZO, 2013).

\subsection{Torno}

De acordo com Oliveira et al. (2017), o torno mecânico "é uma máquina-ferramenta que trabalha com uma combinação de movimentos: a rotação da peça e movimento de avanço da ferramenta cortante. Operado desde o século XIX, é conhecido como o primogênito das máquinas."

Ao longo da história, o torno mecânico sofreu uma grande evolução tecnológica. $O$ primeiro era conhecido como o Torno de Vara, que surgiu no século XIX. Sua estrutura era basicamente uma corda, que uma de suas pontas ficava amarrada em uma vara e a outra enrolada na peça. Para seu funcionamento, bastava levantar a vara e consequentemente a corda subia fazendo com que a peça girasse (OLIVEIRA et al., 2017).

O segundo torno era conhecido como Torno de Fuso. Para seu funcionamento eram necessários dois operadores. Um deles girava a polia, que fazia com que uma correia movimentasse um fuso onde a peça era presa, enquanto a outra segurava sua ferramenta e realizava o corte no material (OLIVEIRA et al., 2017).

O terceiro torno era conhecido como o Torno de Leonardo da Vinci. Este funcionava com uma única pessoa que trabalhava com movimento continuado utilizando o sistema motriz (OLIVEIRA et al., 2017).

Na sua quarta evolução eram conhecidos como Tornos Paralelos, que possuíam vários acessórios. Ele suportava o trabalho com materiais mais duros e dispensava a necessidade de segurar as peças com as mãos. Foi acoplado um motor a ele e adicionaram uma polia escalonada para que pudessem ser feitas as trocas de rotações (OLIVEIRA et al., 2017).

\subsubsection{Torno CNC}

De acordo com Pereira, Azevedo e Abreu (2014): 
O CNC é o comando auxiliado por computador para realizar o processamento dos comandos de máquina. Máquinas ferramentas equipadas com o sistema CNC substituem as máquinas convencionais, devido à necessidade de fabricar peças em lote, obter produtividade, flexibilidade e qualidade superior de acabamento. Estes são os motivos que levaram a automatização do processo de fabricação em máquinas ferramentas, bem como desenvolvimento de ferramentas de diversos materiais, permitindo a usinagem com rapidez. (p.

As máquinas por comando numérico estão um passo à frente no quesito tecnologia, pois estas podem fazer a substituição de ferramentas de modo programado ou até mesmo carregar e descarregar automaticamente, tudo isso sem que o operador interfira no processo (GARCIA; NUNES, 2014).

\subsection{Solda}

Nunes (2019) define o processo de soldagem da seguinte forma:

A soldagem é um dos mais importantes processos industriais de união de peças metálicas. Este processo é essencial para o desenvolvimento de muitos produtos, podendo ser utilizado na fabricação de estruturas simples, como portões, e em componentes com elevado grau de responsabilidade, como os empregados na indústria petrolífera e nuclear. (p. 6)

O sucesso do processo de solda está associado a algumas variáveis, mais especificamente com sua simplicidade e flexibilidade operacional. Apesar de ser um processo simples, ele também pode ser muitas vezes um processo impactante para o material, pois é aplicada uma alta densidade de energia para um volume muito pequeno, causando alterações na sua estrutura e propriedades, tanto dentro da solda como em regiões próximas (BLANCO, 2015).

\subsection{Fresa}

De acordo com Diniz, Marcondes e Coppini (2013), o fresamento é uma operação de usinagem que é caracterizada por uma ferramenta, conhecida como fresa, que possui arestas de corte localizadas simetricamente em torno de um eixo. O movimento de corte consiste na rotação da fresa ao redor do seu eixo, e o movimento de avanço é feito pela peça em usinagem, fixada na mesa da máquina. Após a peça passar pela ferramenta em rotação ela estará com a forma e 
dimensionamento desejado.

Por haver diferentes tipos de fresas, de diferentes formas, a fresadora torna-se diferenciada se comparada a outras máquinas-ferramenta. Uma grande característica da fresadora é a possibilidade de realizar uma gama de trabalhos tridimensionais, além de que o corte pode ser realizado em superfícies situadas tanto em planos paralelos como em planos perpendiculares. (PEREIRA; AZEVEDO; ABREU, 2014)

\subsection{Inspeção}

Segundo a ABNT (2015), inspeção é o "processo de medir, ensaiar e examinar a unidade de produto ou comparar suas características com as especificações.”

A empresa em estudo utiliza a inspeção por variáveis, que de acordo com a ABNT (2015) é a "inspeção segundo a qual uma característica da qualidade em uma unidade do produto é medida em uma escala contínua, tal como quilogramas, metros, metros por segundo, etc., e cada medição é anotada."

\section{MATERIAIS E MÉTODOS}

Para a confecção do presente artigo foi realizado um estudo de caso, sendo que este representa análise intensa de poucos ou um objeto, proporcionando conhecimento detalhado e amplo do assunto em questão. Para a obtenção dos dados cronológicos, foram necessárias visitas técnicas na empresa de usinagem estudada durante 5 dias, no período de 07 horas as 16 horas. As pesquisas bibliográficas foram realizadas em artigos, livros e sites relacionados à usinagem de precisão. Durante esses dias, foi possível verificar e acompanhar todos os processos de fabricação do material de estudo.

A cronoanálise foi empregada para verificar qual processo é o mais eficiente para a produtividade da empresa, visando tempos de produção mais curtos e sem perder a qualidade. Esta é relevante para as empresas, pois a cronometragem do tempo permite estabelecer tempos padrões, médios e normais de produção, obtendo assim, a possibilidade de alcançar um nível mais elevado de produção.

Para este estudo, o tempo de "setup" ou preparação não foi considerado, pois a empresa 
estudada não realiza a contagem deste tempo e não contabiliza em seus cálculos de valor final do produto, ou seja, a empresa só considera o tempo em que a máquina está trabalhando com a ferramenta cortando o material.

Para analisar os dados foi utilizado o software Minitab 18, que é uma ferramenta de análise estatística de melhoria de processos, para ajudar empresas e instituições a identificar inclinações do mercado, resolver problemas e descobrir resultados valiosos nos dados (MINITAB, 2019).

A peça escolhida para o presente estudo é uma Porca Sextavada, confeccionada em aço SAE 1020, tendo um total de 40 itens produzidos. Sua fabricação foi dividida em 7 processos de usinagem e cada processo foi cronometrado.

Através do software Arena 14, foram feitas simulações a fim de descrever os processos de usinagem, analisar os dados obtidos das peças estudadas, identificar qual processo de usinagem possui o maior tempo e realizar um comparativo entre os cenários, sendo um processo simulado conforme cronograma da empresa e o outro contendo as melhorias dispostas pelos autores, baseando-se nos valores da hora-máquina e da matéria-prima.

Para a realização da configuração dos processos no software Arena, foram utilizados os dados coletados para a fabricação das peças do lote em estudo, que posteriormente foram relacionados utilizando o software Minitab $18 \mathrm{em}$ uma tabela para melhor análise dos mesmos, como tempo mínimo, médio e máximo de cada etapa. Os dados coletados e trabalhados foram utilizados para alimentar o modelo lógico (Figura 1) conforme executado atualmente pela empresa. A simulação foi realizada pelo software Arena 14 em um período de 8 horas de trabalho durante 3 dias e a unidade de tempo utilizada foram segundos.

O primeiro processo foi realizado em um Torno Convencional MIN, fabricado pela IMOR, e nele foram executadas as operações de facear e furar. Nestas operações o operador da máquina prende o material bruto com diâmetro de 2.1/4" x 75 milímetros (mm) de comprimento em uma placa de 3 castanhas, usina o material da face da peça apenas para limpar e depois executa a furação com uma broca com diâmetro de $25 \mathrm{~mm}$. 
Figura 1. Modelo lógico de uma empresa de usinagem

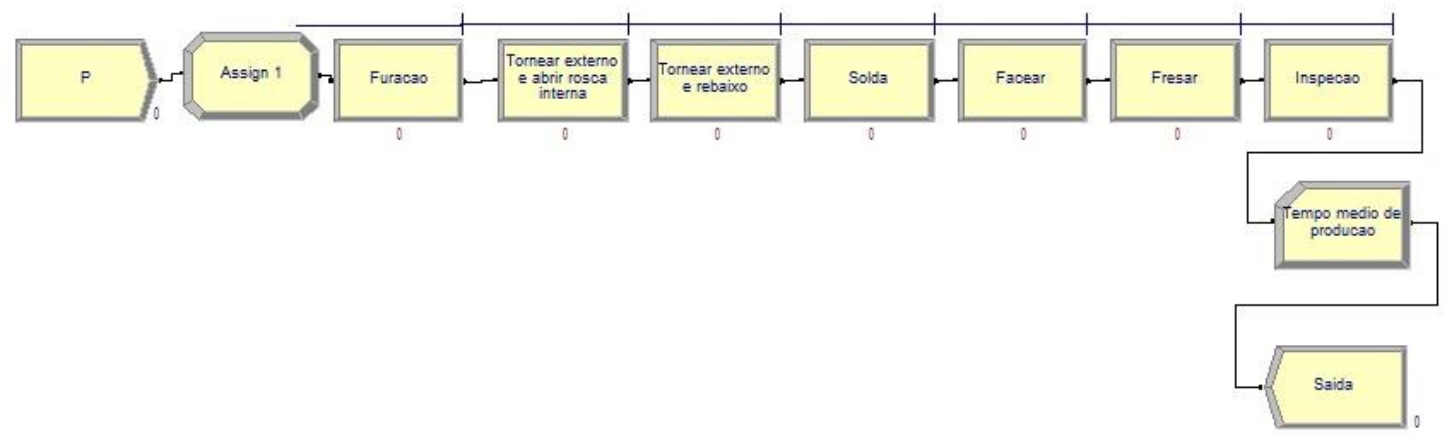

Fonte: Próprios autores (2019).

O segundo foi realizado em um Torno CNC Centur 30D, fabricado pela ROMI, e foram executadas as operações de desbastar o diâmetro externo e usinar a rosca interna. Para executar estas operações o operador prende o material na placa, e com o auxílio de um programa CNC, usina o diâmetro externo, deixando-o com $53,1 \mathrm{~mm}$ e a rosca métrica interna com $30 \mathrm{~mm}$ e passo $3,5 \mathrm{~mm}$.

$\mathrm{O}$ terceiro, realizado na mesma máquina que seu antecessor, consiste em virar a peça e também desbastar o diâmetro externo na mesma medida, e usinar um rebaixo com $36 \mathrm{~mm}$ de diâmetro por $4 \mathrm{~mm}$ de profundidade onde será soldada uma tampa.

Já o quarto processo, foi realizado no setor de caldeiraria, com o auxílio de uma máquina de solda Pulsarc 4000, fabricada pela Eutectic Castolin. Nessa etapa, o soldador utiliza o processo GMAW (Gas Metal ArcWelding), mais conhecido como MIG (Metal Inert Gas) para através de um arame de solda e um arco elétrico unirem as peças através do aquecimento e fusão.

No quinto processo, as peças retornam para o Torno CNC, para facear no comprimento e tirar o excesso de solda, deixando-a com $65 \mathrm{~mm}$, sendo esta sua medida final.

O sexto processo foi realizado na fresadora modelo FVC-40, fabricada pela Cardoso. Nesse processo as peças são presas em uma morsa com o auxílio de um gabarito para garantir os ângulos de $60^{\circ} \mathrm{em}$ todos os lados usinados. Após estarem presas e gabaritadas, as peças são usinadas. $\mathrm{O}$ operador repete o mesmo processo para cada troca de lado até que fique com o formato sextavado.

O sétimo e último processo é o de inspeção da qualidade. Nele, o inspetor utiliza como ferramenta um Paquímetro Quadridimensional Analógico fabricado pela Insize com escala de 0150 mm. O tipo de inspeção feita é a Inspeção por Variável e consiste em comparar o valor lido 
no instrumento com o valor dado no desenho técnico. Após o recebimento das peças, o inspetor climatiza o setor de Controle da Qualidade em temperatura de $20^{\circ} \mathrm{C}$, podendo variar em $2^{\circ} \mathrm{C}$ para mais ou para menos. Depois de climatizadas, as peças são medidas e comparadas com a dimensão nominal no desenho. Estando aprovadas, os processos são finalizados e as peças estão liberadas para embalagem e expedição.

No método proposto pelos autores (Figura 2) a matéria-prima a ser adquirida é perfilada em sextavado, eliminando o processo de fresar e a mesma passaria a ter 6 processos de fabricação. A operação de desbastar o diâmetro externo seria eliminada no segundo e terceiro processos, reduzindo o tempo de operação nesses processos.

Figura 2. Modelo lógico proposto

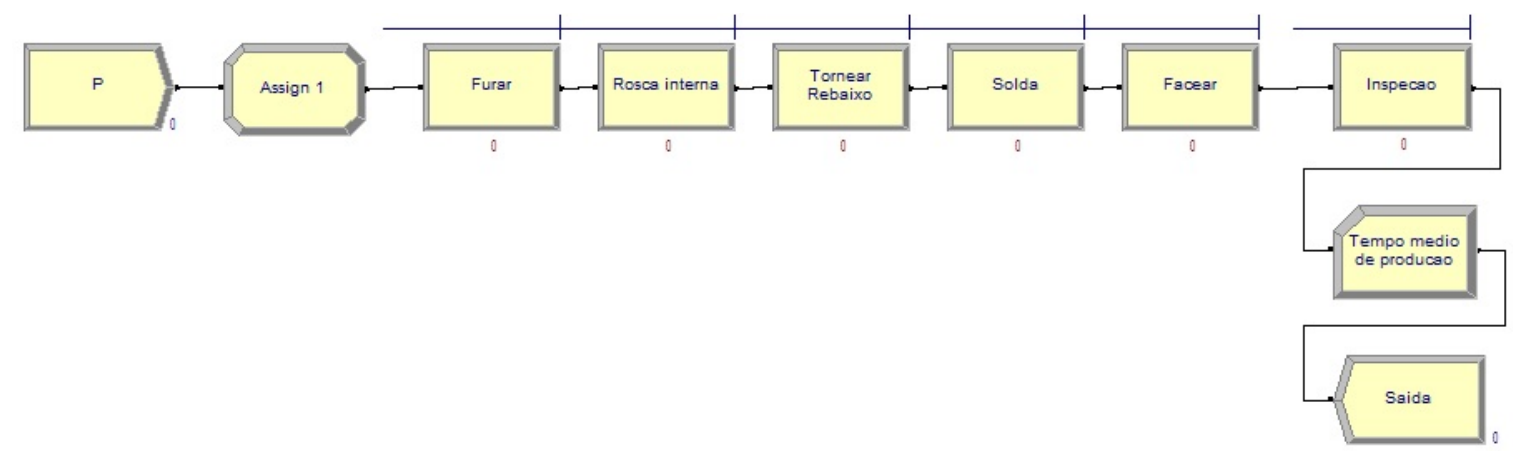

Fonte: Próprios autores (2019).

\subsection{Empresa objeto de estudo}

A empresa utilizada para este estudo é do setor metalúrgico e está instalada em um parque fabril com área superior a $7500 \mathrm{~m}^{2}$, situada no município de Cataguases - MG e possui o certificado de Gestão da Qualidade ISO 9000 desde julho de 2012, conseguindo em 2018 a renovação de sua certificação para a versão 2015, sendo essa a versão mais recente da Norma ISO 9000. Oferece serviços de Usinagem, Caldeiraria, Recuperação, Fabricação de Equipamentos e Usinagem de Campo. Atende a vários segmentos da economia brasileira, tais como: Siderurgia, Mineração, Gráficas, Papel, Produtos Alimentícios, Óleo \& Gás, Têxtil, entre outros. Surgiu em 1986 e implantou o Sistema da Qualidade em 1995.

O arranjo físico da empresa é definido por processo e caracteriza-se como uma prestadora de serviço por não possuir produto próprio. Em seus processos de fabricação, os materiais se 
deslocam de uma máquina para outra até se encerrarem. Desta forma o maquinário atende as necessidades de diversos produtos e os processos se tornam flexíveis.

\section{RESULTADOS E DISCUSSÕES}

Relacionando as informações e dados obtidos na observação do processo de usinagem com o relatório gerado pela simulação no software Arena 14, foram observados alguns pontos.

Em relação a saída de peças do sistema, obteve-se um valor total de 119 porcas, tendo como base os tempos medidos durante os processos em um turno de 8 horas de trabalho por dia.

$\mathrm{Na}$ simulação foi analisado que cada processo possui um tempo de espera (Tabela 1), que é o tempo em que uma peça fica aguardando para dar início no próximo processo, já que sua antecessora ainda está em processo de finalização.

Tabela 1. Tempo médio de espera em cada processo

\begin{tabular}{|l|l|}
\hline \multicolumn{1}{|c|}{ Processo } & \multicolumn{1}{|c|}{ Tempo médio de espera (segundos) } \\
\hline Facear e Furar & 1.7312 \\
\hline $\begin{array}{l}\text { Desbastar o diâmetro externo e usinar a rosca } \\
\text { interna }\end{array}$ & 0.5802 \\
\hline Tornear diâmetro externo e realizar rebaixo & 3.9283 \\
\hline Solda & 0.0000 \\
\hline Facear & 0.00113105 \\
\hline Fresar & 0.1976 \\
\hline Inspeção & 0.0000 \\
\hline
\end{tabular}

Fonte: Próprios autores (2019).

Conforme os tempos de processos gerados no relatório do software Arena 14 e com base no preço de hora-máquina de cada processo (Tabela 2) foram realizados cálculos e obteve-se como resultado uma redução do tempo total de produção de 8,23 minutos que equivale a um ganho de $40,04 \%$ por peça produzida.

No processo original o valor em hora-máquina no lote todo é de $\mathrm{R} \$ 1.517,20$. Enquanto no processo proposto o valor com hora-máquina no lote todo é de $\mathrm{R} \$ 1.022,40$, ou seja, 32,61\% de economia em hora-máquina. 
Analisando-se o valor total de processo, no processo original tem-se um gasto de $\mathrm{R} \$$ 1.517,20 com hora-máquina somando-se a 40 vezes o valor da peça bruta, que é de $\mathrm{R} \$ 8,93$ a unidade, o que resulta em um gasto total de $\mathrm{R} \$ 1.874,40$. Já no processo proposto tem-se um gasto de R \$ 1.022,40 com hora-máquina somando-se a 40 vezes o valor da peça em aço SAE 1020 trefilado em perfil sextavado, que é de $\mathrm{R} \$ 17,00$ a unidade, o que resulta num gasto total de $\mathrm{R} \$$ $1.702,40$. No final, obtem-se uma economia de $\mathrm{R} \$ 172,00$ ou 9,18\% de economia no processo geral.

Tabela 2. Preço da hora-máquina nos processos estudados

\begin{tabular}{|l|l|}
\hline \multicolumn{1}{|c|}{ Processo } & \multicolumn{1}{c|}{ Preço da hora-máquina } \\
\hline Torno convencional & $\mathrm{R} \$ 50,00 /$ hora \\
\hline CNC & $\mathrm{R} \$ 170,00 /$ hora \\
\hline Solda & $\mathrm{R} \$ 45,00 /$ hora \\
\hline Fresa & $\mathrm{R} \$ 170,00 /$ hora \\
\hline Inspeção & $\mathrm{R} \$ 50,00 /$ hora \\
\hline
\end{tabular}

Fonte: Próprios autores (2019).

\section{CONCLUSÃO}

Com base nos resultados obtidos através da comparação entre o modelo original e o modelo proposto, pode-se concluir que o objetivo do trabalho foi alcançado.

Analisando o tempo total de cada modelo, observou-se que no modelo original, o tempo de produção para cada peça era de 21 minutos, já no modelo proposto o tempo para que cada peça fosse produzida era de 12 minutos e 45 segundos, ou seja, houve uma grande redução no tempo de produção da peças, gerando grande impacto no tempo total de produção, em que houve uma redução de $40,04 \%$.

Além da redução no tempo total de produção, houve um ganho econômico de 9,18\%, que dependendo do custo total do processo este pode ser um valor significativo.

Logo, com a implementação deste novo modelo proposto, a empresa seria capaz de obter enormes ganhos tanto financeiros quanto em relação ao tempo de produção, fazendo com que a 
mesma se mantenha competitiva no mercado de usinagem.

\section{REFERÊNCIAS BIBLIOGRÁFICAS}

ABNT. Dossiê técnico. Planos de amostragem - Atributos e variáveis. São Paulo, 2015. Disponível em: http://abnt.org.br/paginampe/biblioteca/files/upload/anexos/pdf/4db42830962766c85068f5c19a41a73d.pdf. Acesso em: 30 maio 2019.

ALMEIDA, Paulo Samuel. Processos de Usinagem - Utilização e Aplicação das Principais Maquinas Operatrizes. 1.ed. São Paulo: Erica, 2015.

BLANCO, Alexandre Jusis et al. Microestrutura e Propriedades Mecânicas de uma junta Soldada obtida por Processo de Soldagem Manual Gas Metal Welding. Unisanta Science \& Technology, v.4, p. 55-63, 2015. CONCEITOS. Competitividade Empresarial - Conceito, o que é, Significado. [S. l.], 2019. Disponível em: https://conceitos.com/competitividade-empresarial/. Acesso em: 20 maio 2019.

DINIZ, Anselmo Eduardo; MARCONDES, Francisco Carlos; COPPINI, Nivaldo Lemos. Tecnologia da usinagem dos materiais. 8. ed. São Paulo: Artliber,2013. 270 p.

GARCIA, F. L.; NUNES, F. de L. Proposta de implantação de manutenção preventiva em um centro de usinagem vertical: um estudo de caso. Tecnologia e Tendências. Ano 13. Vol. 10. № 2. $2^{\circ} \mathrm{sem} .2014$.

NUNES, M. M. Análise e otimização da microestrutura resultante do processo de soldagem com arame tubular para o revestimento de chapas de aço carbono ABNT 1020 com aço inoxidável ABNT 316L. 2019.

OLIVIERA, Edimara Sanches et al. PROJETO DO PRODUTO: UM ESTUDO DE CASO NA PRODUÇÃO DE ARRUELAS POR MÉTODOS ARTESANAIS E TECNOLÓGICOS. Revista Engenharia em Ação UniToledo,v. 2, n. 2, 2017.

PEREIRA, Carlize T.; AZEVEDO, Gabriel S. de; ABREU, Thais F. Retrofitting do controle e implementação do quarto e quinto eixo em uma fresadora CNC de pequeno porte. 2013. $82 \mathrm{f}$. Trabalho de Conclusão de Curso (Tecnologia em Mecatrônica Industrial) - Departamentos Acadêmicos de Eletrônica (DAELN) e Mecânica (DAMEC), Universidade Tecnológica Federal do Paraná. Curitiba, 2014.

PUSAVEC, F. et al. Sustainable machining of high temperature Nickel alloy - Inconel 718: Part 1 - Predictive performance models. Journal of Cleaner Production, v. 81, p. 255-269, 2014.

SARIKAYA, M.; GÜLLÜ, A. Taguchi design and response surface methodology based analysis of machining parameters in CNC turning under MQL. Journal of Cleaner Production, v. 65, p. 604-616, 2014.

USINAGEM BRASIL. PIB recua 0,2\% no primeiro trimestre. [S. l.], 2019. Disponível em:

http://www.usinagem-brasil.com.br/14084-pib-recua-02-no-primeiro-trimestre/. Acesso em: 27 maio 2019. 